\title{
Study on the Development of Tourism Culture in Yunnan*
}

\author{
Mingju Liu \\ Yatai School of Business Management \\ Jilin University of Finance and Economics \\ Changchun, China 130117
}

\author{
Liguang Zhao \\ School of Taxation \\ Jilin University of Finance and Economics \\ Changchun, China 130117
}

\author{
Yanxu Jiang \\ Yatai School of Business Management \\ Jilin University of Finance and Economics \\ Changchun, China 130117
}

\begin{abstract}
Yunnan occupies an important position in China's tourism culture industry. As a major tourism province with tertiary industry tourism as its main economic source, Yunnan is currently facing many problems in tourism and cultural industries. This article studies the development of tourism culture in Yunnan, and discusses how to fully realize the comprehensive upgrade of the tourism industry in Yunnan and puts forward practical suggestions.
\end{abstract}

Keywords-tourism development in Yunnan; cultural construction; tourism culture

\section{INTRODUCTION}

The geographical location of Yunnan is in the southwestern part of China. It is the province with the largest number of ethnic minorities in China, and has rich ethnic folk cultural resources. The special geographical environment features bring abundant and unique natural tourism resources to Yunnan. The folk customs of multiethnic settlements have cast a mysterious veil on Yunnan, which can attract tourists who are interested in unique folk culture. Therefore, how to enhance the attractiveness of Yunnan's tourism industry to tourists, so that the status of the tourism cultural industry in the economic structure of Yunnan continues to improve, and promote its high-quality development is an important issue in front of everyone.

\section{OVER VIEW OF TOURISM CULTURE}

\section{A. The Concept of Tourism Culture}

Due to the gradual rise of tourism, its sustainable development has also attracted everyone's attention. Tourism culture is an emerging theme of tourism culture, which has

*Fund: Social Science project of Jilin Province (2018B81); Project of Jilin Province Education Department in 2020: "Research on development path of rural tourism in Jilin Province under the background of territory tourism"; Jilin University of Finance and Economics 'counselor work excellent project "Study on the cultivation of students' ideals and beliefs from the perspective of internet public opinion". begun to spread in the tourism industry. Because each region has different development experiences and cultural causes, different regions have different cultural heritages from other places, which can become distinct tourism cultural characteristics. Since tourism culture has become a scientific field, it has gradually become the most popular field in the tourism industry.

Through the study of the literature, this article believes that tourism culture is the link between the combination of material and humanistic spiritual products, which connects the subject of tourism, the object and the intermediate medium, brings spiritual enjoyment to the subject of tourism, and injects special connotations into the tourism industry. It is a feeling and enjoyment of the spiritual world and this kind of enjoyment is constantly sought after in today's society. The art, mystery, and uniqueness revealed in the tourism culture can have spiritual resonance and positive and far-reaching effects on tourists.

\section{B. Characteristics of Tourism Culture}

In recent years, the tourism development model has successfully transformed from economic to cultural. Tourism culture has also received widespread attention. And the tourism subject culture also has its own distinctive features, such as epochal character, nationality and mobile communication and class nature. The epochal character means that according to the development of the times, tourism subjects have different requirements for different stages of the tourism industry, and their aesthetic evaluations are not the same, and the differences in the times also produce differences in tourism culture. Nationality is different nationalities in many countries, and the needs of nationalities around the world for tourism culture are also very different. Mobile dissemination means that different cultures continue to spread with the movement of national subjects and merge and spread with each other. Class nature refers to different tourism cultural ideas formed by class 
differences in the same society due to differences in economic income, education level, and living environment.

\section{ThE STATUS QUO OF TOURISM DEVELOPMENT IN YUNNAN AND THE UNIQUENESS OF TOURISM CULTURE}

\section{A. Status of Tourism Development in Yunnan}

1) Continuous improvement of infrastructure: By the end of 2017, there were more than 10,000 different types of tourism companies in Yunnan, with assets estimated to reach 40 billion yuan, and the service business included more than 500 tourist attractions. These include $5 \mathrm{~A}$ national landmarks, more than 600 high-end hotels and 450 ordinary hostels. At the same time, the main tourist routes such as Kunming, Dali and Lijiang have been opened, and tourist railways are currently being formed, including transportation and travel, as well as shopping for all tourism industries in Yunnan.

2) Cultural construction has gradually improved and the market system has gradually improved: In Yunnan's economy, tourism plays a leading role and plays a significant role. Yunnan, as a border region of China, has relatively slow economic development. Affected by different degrees of geographical environment, the development of various industries is not very developed, only tourism is more prominent in economic development, which has promoted the economic development of the entire Yunnan . In 2000, the economy of Yunnan was still very backward, and the proportion of the primary industry was relatively large, but its development was slow. Two years later, the secondary industry has become a major pillar of the economy, followed by the tertiary industry, and the primary industry has gradually become an auxiliary economy, forming a market system with tourism as the main support.

3) Steady growth in total tourism: Since 2000, the Chinese economy has reached a new climax. In 2000, the total revenue of Yunnan's tourism economy was US \$ 339.01 million, of which international tourism was approximately US $\$ 21.143$ billion, and then continued to ensure a high growth trend. In 2010, the total tourism revenue reached US \$ 1141.2414 million, and tourism foreign exchange revenue increased to US \$ 10.0683 million. By 2015, the total revenue of the tourism industry was 5.29 billion US dollars, equivalent to 328.179 billion yuan. In 2017, the total revenue of Yunnan's tourism industry reached 15.6 times that of 2000 .

\section{B. Uniqueness of Tourism Culture in Yunnan}

1) Folk culture is unique and distinctive: As the saying goes, "Ten miles of different manners, a hundred miles of different customs." Custom is a concept closely related to the region. Because Yunnan is home to many ethnic minorities, it best reflects this saying. Cultural tourism resources have distinct folk customs. Taking different wedding customs, festivals, and costumes among ethnic minorities as examples, Yunnan not only has a wellknown Dai Water-splashing Festival, but also Yi Torch Festival and Naxi Sanduo Festival. Various festivals and events are very attractive to tourists to experience different folk cultures. How to make good use of rich folk culture resources and bring immersive tourism experience to tourists is one of the important issues in the study of the development of tourism cultural industry. In terms of clothing, due to the different clothing cultures of various ethnic groups, they can also be integrated into tourism services, allowing tourists to perceive the tourism culture through folk costumes, to obtain a higher level of tourism aesthetics, and to bring tourists a trinity of surround experience.

2) Long and rich tourism history and culture: China is a country with a long history and culture. This land of Yunnan is also full of rich historical ruts. Starting from the first footprint of the ape man, and when Zhuang Qiao entered Yunnan during the Warring States Period, this brought the traditional Central Plains culture into this place full of fantasy and romance in Yunnan, opening it up to the outside world and injecting fresh connotations. Later, the army of the Great Qin Empire arrived here, and then the traces of Yunnan on history books during the dynasties. The historical process and changes that have spread among them are still so impressive. Yunnan's development process is also one of the epitomes of China's development process. It has its own uniqueness in each historical stage, and its integration with Chinese culture constitutes a part of Chinese culture.

3) Unique food culture: Food is the paramount necessity of the people. The Chinese pay attention to eating and have developed a rich and splendid diet culture. Among the six major tourist activities of food, housing, transportation, travel, shopping, and entertainment, food is the most basic and top priority. Yunnan cuisine has its own distinctiveness. They are mainly cooked with mountain cherries, seafood and vegetables. They taste tender and juicy, slightly spicy and hemp. With sour taste, oily taste also has characteristics. At the same time, there are differences in dietary habits among various ethnic groups. At present, Yunnan has some better places in the promotion and promotion of food culture: cross-the-bridge noodles, Steam Pot Chicken, etc.

\section{THE IMPACT OF TOURISM CULTURE ON THE DEVELOPMENT OF YUNNAN}

\section{A. Beneficial to Strengthen the Influence of Yunnan's Cultural Provinces}

Based on the characteristics of the enrichment of its own folk cultural resources, vigorously promoting the historical and cultural tourism routes and folk cultural tourism routes will help strengthen Yunnan's influence as a national cultural province. At the same time, the development of overseas 
traditional ethnic minority festivals that have been commercialized and homogenized. These ceremonies did not really penetrate into the unique cultural level of the nation, lacking the aesthetic connotation and the shining point of folk culture that really moved people's hearts.

\section{B. Excessive Commercialization of Yunnan Local Culture}

As in the over-commercialization of tourism development in many regions, there is also a situation of homogeneous development and over-commercialization in the development of cultural resources in Yunnan. Local folk customs and some pure national cultures lost their original essence and unique color. Under the cloud of commercialization, tourists cannot feel the unique experience brought by the real folk culture itself. At the same time, it also damages folk culture and is not conducive to protection and long-term development of cultural. major economic industry. The government has also given great support to the economy and industry, making full use of the minority culture in Yunnan, building a strong tourism province, fully developing the tourism market in Yunnan, opening up channels for tourists, building a brand image, greatly improving the tourism market competitiveness.

\section{Driving the Economic Development of Local Minorities}

This can not only promote the development of socialist spiritual civilization, but also make the poverty-stricken areas of ethnic minorities free from poverty and become rich. The economic development across Yunnan is uneven, and there are some places full of primitive folk culture, which are often traffic-blocked and poorer areas. Although these places are rich in cultural resources, they have not been properly developed, and many of them are still in the development stage of the primary industry. They are also not very conscious of their own cultural protection, and their culture is not fully protected. If development can be achieved in these areas, it will not only transform the local industrial model, but also increase employment, increase local residents' income, and improve the local economic development. In this regard, this article believes that these areas can be comprehensively developed, including food, housing, transportation, shopping, and entertainment resources, to bring tourists a unique and original tourism experience.

\section{PROBLEMS IN THE DEVELOPMENT OF TOURISM CULTURE IN YUNNAN}

\section{A. The Development Level of Tourism Cultural Resources Is Not High, and Cultural Excavation Is Not Enough}

In the development and construction of tourist cultural resources for tourists in Yunnan, the use of many scenic resources is also in its infancy. The feature that tourists can participate in the entertainment of actual projects cannot meet the needs of modern tourists to regard natural scenery and ethnic culture as high-end and high-quality tourism products. As a result, tourists are limited in their private play time, and tourists are constantly reminded that they need to end the play as soon as possible. Many cultural tourism projects in Yunnan s still focus on repeatedly "performing"

\section{The Economic Foundation for the Development of Tourism and Cultural Industries in Yunnan Is Relatively Weak}

At present, Yunnan still faces the status of backward infrastructure construction. Even in recent years, the aviation and railway construction of Yunnan is in a state of rapid development, but there is still a huge gap with many large cities. There are still significant shortcomings in air and railway construction for international and regional routes. The new road structure and the double backlog placement are not ideal and have accumulated for many years. The grade of the road is low. Rural roads have short mileage and poor rivers. The level of urbanization is relatively small and the structure is unreasonable. Tourism has weak cultural functions. Inadequate infrastructure, such as interest rates, has severely restricted the development of Yunnan's tourism and cultural industries.

\section{The Integration of Tourism and Culture Is Not Deep Enough}

This article learns that the current degree of cultural development of tourist destinations and attractions in Yunnan is too low. Many regions and industry developers have a low level of understanding of the tourism industry, and their consciousness of thinking is still in the early stages of tourism development. Developers blindly pursue shortterm benefits, do not consider the status of industrial development, ignore the precious and characteristic folk cultural resources in the tourism industry in Yunnan, and lack the thinking of linking the cultural industry and the tourism industry. When tourists expect to experience the local real and sensible culture from the tourism process, they find that they lack the high-level and in-depth tourism cultural products and corresponding services, and they will feel dissatisfied. A large amount of homogenized content hurts the content of truly valuable cultural resources.

\section{E. Tourism Cultural Talents Are Scarce and Their Vision Is Narrow}

To build a high-end route in the service industry, the presence of high-end service employees is indispensable. 
The development of cultural tourism must attach importance to the cultivation of people. The current dilemma facing the tourism industry in Yunnan is largely due to the lack of talent. Specifically, on the one hand, the product developer of the tourism culture is absent, the talents of management and planning are shortage, and the lack of high-end talents and developers dedicated to the development of the cultural tourism industry. On the other hand, the grass-roots practitioners in the tourism industry, such as tour guides and attractions service workers, have remained at a relatively low level of service for a long time and have not improved with the development of the industry. These objective problems have become a pain point to curb the development of the tertiary industry represented by tourism in Yunnan in a better direction.

\section{SugGestions to PROMOTE THE DEVELOPMENT OF TOURISM CULTURE IN YUNNAN}

\section{A. Increasing Investment in Tourism and Cultural Industries}

The Chinese government of Yunnan should step up its efforts to strengthen public infrastructure construction, investment and financing reform mechanisms. According to marketing, cultural tourism is incorporated into cultural status, government markets, businesses and decision-making are established, risk management is strengthened, the formation of diversified investment entities, diversified investment mechanisms, diversified investment and financing system investments can achieve maximum efficiency for long-term solutions in tourism and tourism. At the same time, Yunnan must strengthen its organizational leadership system, sound market system, laws, rules and regulations, improve tourism, and promote the development of tourism.

\section{B. Improving the Cultural Literacy of Tourists and Staff}

In the high-level spiritual enjoyment activity that cultivates the body and mind, the cooperation of tourists and staff is very important. But this cooperation is not only related to the professionalism and high-quality service concept of staff, but also to the good quality of individual tourists. As for the cultural quality of the staff, if there is no clear cultural education, it will not be more conducive to the promotion of tourism culture for travelers, thereby reducing the quality of the tourism industry. The state can improve laws and regulations to effectively supervise and supervise the service behavior of staff members and put services on the bright side. For tourists, they can be infiltrated from the educational level to enhance their cultural literacy. Finally, the mutual cooperation between tourists and service personnel is achieved, which is conducive to the healthy development of the tourism industry.

\section{Strengthening the Promotion and Construction of Tourism Culture}

It is necessary to actively promote the tourism industry's propaganda and cooperation, concentrate resources and strengths in various aspects, and strengthen the implementation of "exit" and "inviting" advertising campaigns. It is necessary to accelerate the development of tourism culture, actively establish a tourism culture platform, connect the Internet, radio, television, and the print media, and set up a multilingual tourism marketing system in Yunnan. It is necessary to give full play to the propaganda role of tourism culture festivals, and organize comprehensive and extensive tourism culture promotion activities by organizing different tourism festivals, tourism culture fairs, and publicity activities. It is necessary to actively participate in cultural events, tourism promotions and exhibitions in major client countries of the world, and to hold domestic and external tourism conferences and briefings as appropriate, and widely publicize rich cultural resources.

\section{Improving the Construction of Tourism Cultural Product System and Tapping the Connotation of Tourism Culture}

At present, China supports the development of tourist cities along the One Belt One Road. The development of platform and regional linkage is positive and obvious to the promotion of industrial development in tourist areas. Of course, strengthening regional tourism cooperation depends on the government's policy guidance and support, and builds an interactive communication platform through the government. The functional departments of the government should give active help and fully coordinate consultations to achieve the characteristic and integrated development of the entire industry. The development of the tourism industry is inseparable from planning. In order to achieve the goal of unified coordination, it is necessary to organize specialized functional agencies to conduct research on the development direction of regional tourism on the basis of sufficient research, draw reasonable conclusions and make decisions, and implement them in a timely manner. In the later stage, it is necessary to evaluate the decision results and form a phased development report. In terms of creating a distinctive and attractive tourism and cultural product brand, it is necessary to rely on the reality of Yunnan, understand consumers 'aspirations, and reasonably coordinate the history and folklore culture of Yunnan with industrial development.

\section{E. Cultivating Talents in the Tourism Culture Industry}

Talent is valuable. At present, there is a serious shortage of talents in the tourism and cultural industry in Yunnan and talents are the foundation of its development. In order to continue to develop the cultural industry, it is necessary to extensively absorb tourism professionals who are pragmatic, practical, enterprising, high-quality, and capable. It is necessary to conscientiously implement and effectively implement the strategy of "rejuvenating tourism through talents" and put the "six batches" strategy into practice. It is necessary to rationally and systematically specify the planning for the absorption and development of human resources, and to explore a set of human resources development systems that are suitable for the conditions of Yunnan, supported by the country and in line with international standards. It should also be noted that the talent absorption plan of the cultural industry sector must be complementary to the talent training plans of other sectors in 
China, such as the education sector and the agricultural sector. Only through mutual support and cooperation can the government implement the large-scale plan for human resource development more efficiently.

\section{CONCLUSION}

Through research and investigation, it is concluded that the tourism cultural industry is a high-end emerging industry that now provides tourists with a variety of tourism services and products, relying on markets and resources. At the same time, it is also a collision between the tourism industry and the cultural industry, which promotes the development of modern economic industries. It is of great significance to the upgrading of Yunnan's economic and cultural industries, as well as international cultural exchanges and tourism cooperation.

\section{REFERENCES}

[1] Feng Naikang. Minutes of the First Symposium on Chinese Tourism Culture [J]. Tourism Tribune 2018, (1): 23-24. (in Chinese)

[2] Fan Yongni. Practice and Reflection on Yunnan National Culture Industry [J]. Journal of Yunnan Nationalities University, 2016 (11): 99-103. (in Chinese)

[3] Wang Zhiyong, Zhao Yue. Research on Financial Support for Sustainable Development of Tourism and Cultural Industry in Yunnan [J]. Inquiry into Economic Issues, 2017 (7): 113-116. (in Chinese)

[4] Wang Xiaohui. Research on Countermeasures to Enhance the Competitiveness of Yunnan Tourism Culture Industry [J]. Tourism Economy, 2016: 99-104. (in Chinese)

[5] Ma Xiangqing. Tourism Culture [M]. Shanghai Jiao Tong University Press, 2016 (07). (in Chinese)

[6] Zhang Guohong. Chinese Cultural Tourism [M]. Nankai University Press, 2016 (01). (in Chinese) 